\title{
Expression of an inaccessible P1.7 subtype epitope on meningococcal class 1 proteins
}

\author{
E. WEDEGE, R. DALSEG, D. A. CAUGANT, J. T. POOLMAN* and L. O. FRØHOLM
}

National Institute of Public Health, Geitmyrsveien 75, 0462 Oslo 4, Norway and * National Institute of Public Health and Environmental Protection, Antonie van Leeuwenhoeklaan 9, PO Box 1, 3720 BA Bilthoven, The Netherlands

\begin{abstract}
Summary. Dot-blot analysis of whole-cell suspensions of meningococci showed that $81 \%$ of B : 15:P1.16 strains from patients reacted with a monoclonal antibody (MAb) against subtype P1.7. The remaining strains, which did not react on dot-blots or in ELISA, demonstrated the P1.7 subtype epitope on immunoblots after denaturation of the cells with sodium dodecyl sulphate. The monomeric class 1 proteins of the two P1.16 subtype variants had slightly different mol. wts, but bound the P1.7 antibody equally well. These results were explained by a deletion of three codons in the gene encoding the first variable region of the P1.16 class 1 protein. The deletion accounted for the non-exposure of the P1.7 epitope on native cells. Other patient strains, with subtypes P1.3, P1.9 or without any known subtype, also showed a binding site for the P1.7 MAb, which became available only after denaturation. Demonstration of inaccessible epitopes may have consequences for subtype designations and vaccine development.
\end{abstract}

\section{Introduction}

The class 1 protein is one of the major outermembrane proteins of Neisseria meningitidis, and antigenic variations of this protein define the subtype of a meningococcal strain. ${ }^{1}$ To date, monoclonal antibodies (MAbs) have been made against c. 15 different subtypes, ${ }^{1-8}$ and the binding of two different subtype MAbs to some class 1 proteins has been demonstrated. ${ }^{4,8-10}$

Expression of the class 1 protein is controlled by the por $A$ gene. ${ }^{11}$ The predicted amino-acid sequence of the gene shows homology with the gonococcal PI pore proteins, ${ }^{12,13}$ and a pore function with a slight cationic selectivity has been demonstrated in vitro. ${ }^{14}$ Two major variable regions are present in the amino-acid sequences of different class 1 proteins in which the subtype-specific epitopes are localised. ${ }^{13,15}$ Thus, the subtype P1.7,16 protein of the prototype strain $44 / 76$ has the epitopes for the subtypes P1.7 and P1.16 MAbs in the first (VR1) and the second (VR2) variable region, respectively. ${ }^{15}$ Both regions are exposed on the cell surface, since the MAbs bind to whole cells and are bactericidal. ${ }^{16}$

A dot-blot study of whole-cell suspensions of meningococci ${ }^{17}$ showed that many $\mathrm{B}: 15: \mathrm{P} 1.16$ strains from Norwegian patients also reacted with the P1.7 subtype MAb. This was similar to the prototype strain $44 / 76$ of serotype 15 , which was originally isolated in Norway. ${ }^{18}$ The remaining B:15:P1.16 strains did not react, but preliminary studies with a few such strains

Received 9 Dec. 1991; revised version accepted 30 April 1992. indicated binding of the P1.7 MAb after denaturation and immunoblotting. ${ }^{17}$

In this study, we examined the reactions of more B: $15: P 1.16$ strains and strains of other subtypes with the P1.7 MAb in dot-blotting, ELISA and immunoblotting. The reason for the inaccessibility of the epitope in some strains was examined by DNA sequencing.

\section{Materials and methods}

\section{Meningococcal strains}

The serotypes and subtypes of 50 patient and 133 carrier strains, collected in Norway during 1987-1988, have been described previously. ${ }^{9}$ One hundred and one strains from Norwegian patients, collected during 1988-1990, 87 strains from various other parts of the world, ${ }^{19}$ and three patient strains from Chile were also studied.

\section{Monoclonal antibodies}

P1.Ham MAb was supplied by Dr F. E. Ashton. MAbs against serotype 15 (3-1-P15), subtypes P1.3 (12-1-P1.3) and P1.16 (3-1-P1.16) were supplied by Dr W. D. Zollinger. MAbs against subtypes P1.6 (MN19D6.13), P1.7 (MN14C11.6) and P1.9 (MN5A10F) were supplied by author J.T.P.

\section{Dot-blotting and immunoblotting}

These procedures were performed with whole-cell suspensions as described previously. ${ }^{9}$ The cells were 
initially heat inactivated at $56^{\circ} \mathrm{C}$ for $30 \mathrm{~min}$ in phosphate-buffered saline. ${ }^{20}$ Binding of the MAbs to the blotted antigens was detected with rabbit anti-mouse immunoglobulin conjugated to horseradish peroxidase (Dakopatts a/s, Denmark). ${ }^{9}$ Cells used as antigens in immunoblotting were either fully denatured by boiling with sample buffer ${ }^{21}$ containing 2-mercaptoethanol and SDS $0.7 \%$ or denatured mildly by mixing with ice-cold sample buffer just before application on to SDS-PAGE gels containing acrylamide $12 \%$. The dilutions of the P1.7 MAb used in dot-blotting and immunoblotting were 1 in 60000 and 1 in 20000 . respectively. Mol. wt determinations were performed with a calibration kit from Pharmacia AB. Sweden.

\section{ELISA}

Heat-inactivated cell suspensions served as antigens in ELISA, which was performed as described previously. ${ }^{9}$ The P1.7 MAb was diluted 1 in 10000 .

\section{Enzlme electrophoresis}

Each of the 374 isolates was characterised by multilocus enzyme analysis with starch gel electrophoresis and enzyme-specific staining. ${ }^{22}$ The assignment of the isolates to the ET-5 complex was based on the analyses of 14 different enzyme loci. ${ }^{23}$

\section{Polymerase chain reactions}

Chromosomal DNA was isolated as described previously, ${ }^{24}$ except for an additional treatment of the DNA solution for $2 \mathrm{~h}$ with boiled RNAase A (Sigma) $20 \mu \mathrm{g} / \mathrm{ml}$ before the second phenol-chloroform extraction. DNA concentration and purity were determined spectrophotometrically and electrophoretically. The primers, which were synthesised by the Biotechnology Centre. Oslo, were P-1182/1159as 5'-TTA GAA TTT GTG GCG CAA ACC GAC-3'. which corresponded to the anti-sense strand of the region encoding the seven $\mathrm{C}$-terminal amino acids of the class 1 protein and the TAA stop codon, ${ }^{13}$ and P10/27s 5'-AAA CTT ACC GCC CTC GTA-3', which coded for amino acids 4-9 of the signal peptide.

The polymerase chain reactions (PCRs) were performed as described by Maiden et al. ${ }^{13}$ except that the concentration of the primers was $0.2 \mu \mathrm{M}$ to prevent nonspecific binding. The annealing temperature was $60^{\circ} \mathrm{C}$

\section{Sequencing of $P C R$ products}

PCR products were separated from the primers by centrifugation through Chroma Spin + TE 100 columns (Clontech Labs, CA. USA). The sequencing primer was $\mathrm{P} 10 / 27 \mathrm{~s}$, which was labelled with $\left(\gamma^{-32} \mathrm{P}\right)$ ATP. and was used without purification as described by Embley. ${ }^{25}$ The composition of the sequencing reaction mixtures was as reported by Embley, ${ }^{25}$ but
$4 \mu \mathrm{l}$ of $10 \times$ concentrated Taq-polymerase buffer was used; $4 \mu \mathrm{l}$ of the reaction mixture was added to each of four tubes with $4 \mu \mathrm{l}$ of termination mixture. This mixture was as follows: for the A reaction- $333 \mu \mathrm{M}$ ddATP, $15 \mu \mathrm{m}$ dATP and $50 \mu \mathrm{m}$ each of dGTP, dCTP and dTTP; for the G reaction-250 $\mu \mathrm{M} \mathrm{ddGTP,} 15 \mu \mathrm{M}$ dGTP and $50 \mu \mathrm{M}$ each of dATP, dCTP and dTTP; for the $\mathrm{C}$ reaction $-333 \mu \mathrm{m}$ ddCTP, $15 \mu \mathrm{m} \mathrm{dCTP}$ and $50 \mu \mathrm{m}$ each of dATP, dGTP and dTTP; and for the T reaction-666 $\mu \mathrm{M}$ ddTTP, $15 \mu \mathrm{M}$ dTTP and $50 \mu \mathrm{m}$ each of dATP, dCTP and dGTP. Each tube was overlaid with one drop of light mineral oil. The sequencing reactions were performed by PCR. ${ }^{25}$ The samples were left at $4^{\circ} \mathrm{C}$ before the addition of $4 \mu \mathrm{l}$ of formamide stop buffer (Boehringer Mannheim, Germany). One $\mu \mathrm{l}$ of each reaction mixture was analysed in $40-\mathrm{cm}$ lengths of polyacrylamide $6 \%$ sequencing gels. The gels were fixed and dried at $80^{\circ} \mathrm{C}^{25}$ and autoradiographed for $14 \mathrm{~h}$ with Hyperfilm-MP (Amersham International).

\section{Results}

\section{$15:$ P1.16 strains}

Dot-blotting with specific MAbs showed that $15: \mathrm{Pl} .16$ was the most frequent serotype and subtype combination among 151 strains collected from Norwegian patients during 1987-1990. These strains constituted $46 \%$ ( 69 of 151) of the case strains (table); all were serogroup B. Fifty-six $(81 \%)$ of the 15:P1.16 strains also reacted with the P1.7 MAb on dot-blots and, therefore, had subtype P1.7,16, whereas $13(19 \%)$ of the strains had no reaction (table). In ELISA, the latter strains showed no binding of the P1.7 MAb. These analyses were performed with bacteria that had been inactivated at $56^{\circ} \mathrm{C}$ for $30 \mathrm{~min}$ and stored as cell suspensions at $4{ }^{\circ} \mathrm{C} .{ }^{20}$ The binding patterns on dotblots of strains representing the two different subtypes P1.16 and P1.7.16 with the P1.16 and P1.7 MAbs are shown in fig. 1A. All strains expressed similar levels of class 1 proteins in SDS-PAGE gels.

When cell suspensions of strains with the two kinds of subtypes were boiled with SDS-containing sample buffer before gel electrophoresis, the monomeric class 1 proteins reacted equally well with the P1.7 MAb on immunoblots. However, their mol. wts were slightly different (fig. 1B). The P1.7,16 subtype protein had a mol. wt of $42.3 \times 10^{3}$, whereas that of the $\mathrm{P} 1.16$ subtype protein was $41.6 \times 10^{3}$. Both subtype epitopes were present on the same antigen. This was shown by splitting the nitrocellulose strip from one blotted lane and incubating each half with the P1.7 and P1.16 MAbs, respectively (fig. 2). All 13 patient strains with subtype P1.16 showed a binding site for the P1.7 MAb which became available only after denaturation of the antigens (table).

To examine whether less harsh denaturation of the cells before immunoblotting would give the same response as the more native antigens on dot-blots, cells 
Table. Reaction of meningococcal strains with the P1.7 subtype-specific MAb in dot-blotting and immunoblotting

\begin{tabular}{|c|c|c|c|c|}
\hline \multirow{3}{*}{ Strains } & \multirow{3}{*}{$\begin{array}{l}\text { Number of } \\
\text { strains }\end{array}$} & \multicolumn{3}{|c|}{ Number of strains with reactions on } \\
\hline & & \multicolumn{2}{|c|}{ dot-blots } & \multirow{2}{*}{$\begin{array}{c}\text { immunoblots* } \\
\text { P1.7+ }\end{array}$} \\
\hline & & P1.7+ & P1.7- & \\
\hline $15:$ P1.16 from patients & 69 & 56 & 13 & $13 \dagger$ \\
\hline $15: P 1.16$ from carriers & 3 & 1 & 2 & $2 \dagger$ \\
\hline 15:- from patients & 15 & 3 & 12 & $4 \dagger$ \\
\hline 15:- from carriers & 7 & 0 & $7+$ & 0 \\
\hline $\begin{array}{l}\text { With subtype } \mathrm{P} 1.3 \\
\text { from patients }\end{array}$ & 8 & 0 & 8 & $5 \S$ \\
\hline $\begin{array}{l}\text { With subtype P1.3 } \\
\text { from carriers }\end{array}$ & 18 & 0 & 18 & 0 \\
\hline $\begin{array}{l}\text { With subtype P1.9 } \\
\text { from patients }\end{array}$ & 13 & 1 & 12 & $1 \|$ \\
\hline Other strains & 241 & 18 & 223 & ND \\
\hline Total & 374 & & & \\
\hline
\end{tabular}

The strain collection included 151 patient and 133 carrier strains from Norway and 90 patient strains from other countries.

ND, not determined.

* Immunoblotting was performed with all strains not reacting with P1.7 MAb on dot-blots (P1.7 - strains).

+ Belonged to the ET-5 complex, reacted with P1.Ham.

¥ All had subtype P1.6.

$\S$ Belonged to the ET-5 complex, two strains reacted with P1.Ham.

\| Reacted with P1.Ham.

A

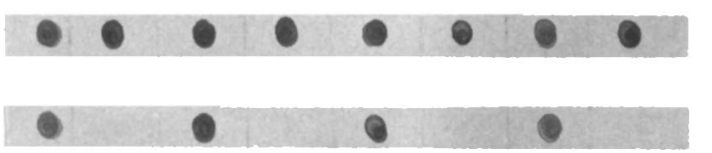

B

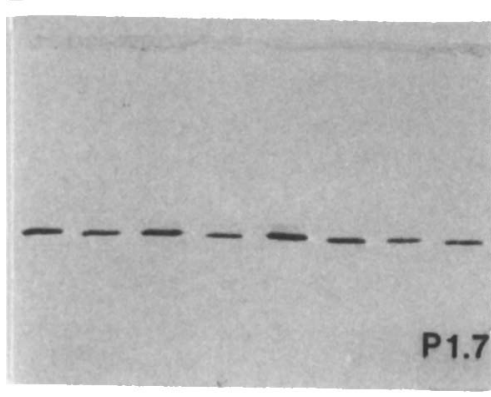

C

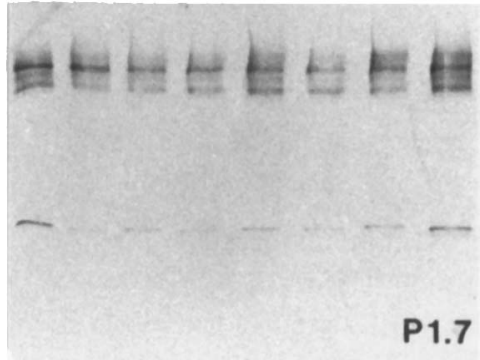

Fig. 1. Dot-blots (A) and immunoblots (B and $\mathbf{C})$ of whole-cell suspensions of 15:P1.16 strains with surface-exposed or masked P1.7 subtype epitopes, respectively, applied in every second position. Reference strain 44/76 with subtype P1.7,16 was applied in the first position on all blots. Dot-blots were incubated with the P1.7 and P1.16 MAbs and immunoblots with the P1.7 MAb. In B, the cells were denatured by boiling with sample buffer before SDS-PAGE, ${ }^{21}$ and in $\mathbf{C}$, the same cells were denatured mildly by mixing with cold sample buffer before application on to the gel. B shows the two immunoreactive monomeric class 1 proteins of slightly different mol. wts; $\mathbf{C}$ shows the polymeric class 1 proteins with traces of the monomeric proteins. MAb binding was detected with peroxidase-conjugated antibodies.

with the two subtype proteins were denatured mildly by mixing with cold sample buffer containing SDS before electrophoresis. Several high mol. wt bands reacting with the P1.7 MAb were observed with a trace of monomeric class 1 proteins (fig. 1C). Strains with the two kinds of subtype proteins showed a similar pattern and intensity of the polymeric immunoreactive bands. Thus, mild denaturation of the antigens with SDS was sufficient to expose or unmask the epitope for binding with the P1.7 MAb.

The finding of an intact P1.7 epitope in such P1.16 strains and also the lower mol. wt of their class 1 protein suggested the possibility of a deletion in the protein. DNA was extracted from three B:15:P1.16 strains with masked $\mathrm{P} 1.7$ epitope. The extracted DNA was subjected to PCR and the products were sequenced as detailed above. The three strains had identical nucleotide sequences in VR1 of the protein in which the P1.7 epitope is located. ${ }^{15,16}$ The nucleotide sequence and the resulting amino-acid sequence of VR1 are shown in fig. 3. When the strains with a masked P1.7 epitope were compared to the corresponding amino-acid sequence of the $P 1.7,16$ protein from the reference strain $44 / 76,{ }^{15}$ all had a deletion of 


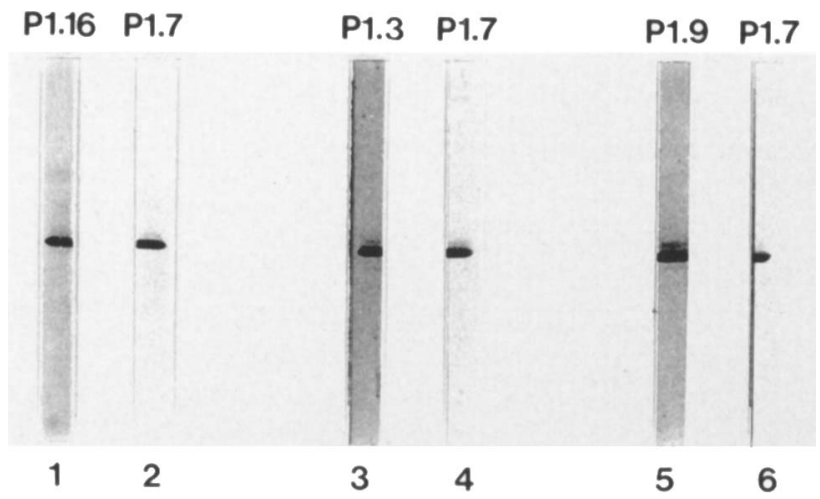

Fig. 2. Immunoblots of 15:P1.16 (lanes 1 and 2). 15:P1.3 (3 and 4) and $4: P 1.9$ (5 and 6 ) strains with masked P1.7 epitopes. Whole-cell suspensions of the strains were boiled with sample buffer before SDS PAGE. Nitrocellulose strips, obtained by blotting of each strain. were divided in two and each half was incubated with different subtype MAbs as shown: lane 1 with P1.16 MAb: 3 with P1.3 MAb: 5 with P1.9 MAb, 2, 4 and 6 with P1.7 MAb. The subtype Pl.3 and P1.9 MAbs were incubated in the presence of Empigen BB $0.25 \%$ to increase antibody binding. ${ }^{26.2 \%}$

three amino acids next to the identified P1.7 epitope. ${ }^{15.16}$

When the enzyme genotypes of the strains were determined by multilocus enzyme electrophoresis, all Norwegian 15:P1.16 patient strains with the masked P1.7 epitope were shown to belong to the ET-5 complex. ${ }^{28}$ They also reacted with the PI.Ham MAb on dot-blots (table). The 15:P1.7,16 strains had similar genotype, but $18 \%$ of these did not bind the P1.Ham $\mathrm{MAb}$. which suggested further subtype variations within this group of strains. Two 15:P1.16 carrier strains, which also showed an inaccessible P1.7 epitope. were ET-5 and bound the P1.Ham MAb (table).

\section{Strains with other subtypes}

We examined other strains which were ET-5 and bound the Pl.Ham MAb for carriage of a masked P1.7 epitope. Fifteen Norwegian patient strains of serotype 15 did not react with the P1.16 MAb on dotblots (designated as 15 :- strains in the table). They all belonged to the ET-5 complex and bound the P1.Ham $\mathrm{MAb}$. Three of the strains had a surface-exposed P1.7 epitope as shown by binding of the P1.7 MAb on dotblots (table). Immunoblotting of the 12 remaining strains showed that four $(33 \%)$ strains reacted with the P1.7 MAb after denaturation and thus carried a masked P1.7 epitope. In contrast, none of the 15:isolates from carriers in our collection reacted with the P1.7 reagent on blots (table). They had a different subtype, previously defined as subtype $\mathrm{P} 1.6 ;^{4.7}$ they did not belong to the ET-5 complex, and only one strain bound the Pl.Ham MAb. The serotype 15 protein of these carrier strains had a lower mol. wt in SDS gels than the corresponding class 3 protein from 15:- patient strains, which indicated differences in the serotype 15 proteins.

Some meningococci with other subtypes also expressed a masked P1.7 epitope. Five patient strains of subtype P1.3 from Chile and one Swiss strain with subtype P1.9, which did not bind the P1.7 MAb on dot-blots or in ELISA, reacted after immunoblotting (table). The mobilities of the class 1 protein bands reacting with each pair of MAbs were similar, as shown in fig. 2. The strain from Switzerland and two of the Chilean strains bound the P1.Ham MAb, and all the Chilean strains belonged to the ET-5 complex. The other patient or carrier strains with subtypes P1.3 or P1.9 did not bind the P1.7 MAb on immunoblots (table), nor did they belong to the ET-5 complex or react with the Pl.Ham $\mathrm{MAb}$.

None of the prototype strains, ${ }^{1}$ including that for subtype P1.9 (M982), revealed a masked P1.7 epitope on immunoblots.

\section{Discussion}

This report describes an epitope for the P1.7 subtype-specific MAb on some meningococci which is unavailable for antibody binding with intact cells when they are examined by dot-blotting and ELISA methods. The epitope, which was expressed by meningococci of different subtypes, was exposed only after denaturation of the cells with SDS, but not after heat inactivation at $56^{\circ} \mathrm{C} .^{20}$ After denaturation, class 1 proteins with the masked P1.7 epitope reacted as strongly with the P1.7 MAb as strains recognising the $\mathrm{MAb}$ in the native state, which indicated that the epitope was intact.

For Norwegian B:15:P1.16 patient strains which carried a masked P1.7 epitope, a deletion of three amino acids in VR 1 of the class 1 protein was the most likely explanation for these findings. VR 1 is located in loop 1 of the monomeric protein. ${ }^{13.16}$ This loop is the longest and contains the linear epitope for the P1.7 MAb at its tip. ${ }^{16} \mathrm{~A}$ deletion will shorten the loop and pull the epitope somewhat closer to the outer membrane so that it may be masked by the other loops or by other molecules, e.g., LPS. ${ }^{29-31}$ SDS altered this

\begin{tabular}{|c|c|c|c|c|c|c|c|c|c|c|c|c|c|c|c|c|c|c|c|c|c|c|}
\hline & $G C$ & $C A A$ & $\mathrm{GCC}$ & GCT & $\mathrm{AAC}$ & GGT & $\mathrm{GGA}$ & GCG & $\mathrm{AGC}$ & GGT & $\mathrm{CAG}$ & GTA & AAA & GTT & $\mathrm{ACT}$ & $\mathrm{AAG}$ & $\ldots$ & & $\ldots$ & $\mathrm{GCC}$ & AAA & $A G C$ \\
\hline$P\left(16^{*}\right.$ & $A$ & $Q$ & $A$ & A & $\mathrm{N}$ & G & $\mathrm{G}$ & A & $\mathrm{S}$ & $\mathrm{G}$ & $Q$ & $\mathrm{~V}$ & $\mathrm{~K}$ & $\mathrm{~V}$ & $\mathrm{~T}$ & K & . & . & . & A & K & $\mathrm{S}$ \\
\hline P: .7 .16 & A & $Q$ & A & A & $\mathrm{N}$ & G & $\underline{\mathrm{G}}$ & A & $S$ & G & $Q$ & $\mathrm{~V}$ & $\mathrm{~K}$ & V & $T$ & $\mathrm{~K}$ & V & $\mathrm{T}$ & $\mathrm{K}$ & A & $\mathrm{K}$ & $\mathrm{S}$ \\
\hline
\end{tabular}

Fig. 3. Vucleotide and deduced amino-acid sequences of the VR1 domain of the gene coding for the class 1 subtype P1.16 protein with a masked P1.7 epitope. Compared to the amino-acid sequence of VRl of the subtype P1.7,16 protein, ${ }^{15.16}$ a deletion of three amino acids is observed. Deleted residues are indicated by dots, and the defined P1.7 epitope ${ }^{15}, 16$ is underlined. Except for the deleted residues, the deduced amino-acid sequence of the P1.16 protein was identical to that of the P1.7.16 protein ${ }^{15}$ up to amino acid no. 109 . which represents the limit of sequence information obtained with the primer used. 
conformation and, as a result, made the epitope available for antibody binding.

Approximately $20 \%$ of the Norwegian B: $15:$ P1.16 strains had the subtype variant with the masked P1.7 epitope. There was some evidence for a restricted geographical localisation as three of five such strains, isolated in 1987 and 1988, were from patients in a restricted coastal region in western Norway. Such strains were also isolated from two brothers, who developed meningococcal disease, which suggested that this subtype variant may be a valuable epidemiological marker.

All 15:P1.16 strains from Norway with a masked P1.7 epitope belonged to the ET-5 complex ${ }^{28}$ which consists of genetically closely related clones of sulphonamide-resistant meningococci, which have been causing epidemics in various parts of the world. ${ }^{32}$ These strains also bound the MAb against P1.Ham, a class 1 subtype epitope, which is associated with meningococcal strains from Hamilton, Canada. ${ }^{5}$ Most strains with subtype P1.3, P1.9 or non-subtypable serotype 15 isolates which carried a masked P1.7 epitope had the same multilocus enzyme genotype and reacted with the P1.Ham MAb. A previous study of subtype combinations ${ }^{17}$ showed an association between the P1.7 and P1.Ham epitopes. These results suggest that the P1.Ham epitope may serve as a marker for most strains with either an exposed or a masked P1.7 epitope.

Previously, a Chilean strain of subtype P1.3 was found to react in ELISA with the P1.7 MAb, ${ }^{4}$ but the binding was weaker than that of various other strains reacting with this MAb. In the present study, five further Chilean strains of subtype P1.3 showed no binding of the P1.7 MAb in ELISA. If the masked P1.7 epitope is located in VR1 of these P1.3 subtype proteins, as has been demonstrated for the accessible

\section{References}

1. Frasch CE, Zollinger WD, Poolman JT. Serotype antigens of Neisseria meningitidis and a proposed scheme for designation of serotypes. Rev Infect Dis 1985; 7: 504-510.

2. Zollinger WD, Moran EE, Connelly H, Mandrell RE, Brandt B. Monoclonal antibodies to serotype 2 and serotype 15 outer membrane proteins of Neisseria meningtidis and their use in serotyping. Infect Immun 1984; 46: 260-266.

3. Abdillahi H, Poolman JT. Neisseria meningitidis group B serosubtyping using monoclonal antibodies in whole-cell ELISA. Microb Pathog 1988; 4: 27-32.

4. Abdillahi H, Poolman JT. Definition of meningococcal class 1 OMP subtyping antigens by monoclonal antibodies. FEMS Microbiol Immunol 1988; 47: 139-144.

5. Ashton FE, Ryan JA, Diena BB, Zollinger WD. Monoclonal antibody analysis of meningococcal disease strains isolated in Canada. In: Poolman JT et al. (eds) Gonococci and meningococci. Dordrecht, Kluwer Academic Publishers. 1988: 15-18.

6. Calain P, Poolman J, Zollinger W et al. Serological study of meningococcal isolates in Switzerland and France 19801986. Eur J Clin Microbiol Infect Dis 1988; 7: 788-791.

7. Poolman JT, Abdillahi H. Outer membrane protein serosubtyping of Neisseria meningitidis. Eur J Clin Microbiol Infect Dis 1988; 7: 291-292.

8. Ashton FE, Mancino L, Ryan AJ, Poolman JT, Abdillahi H, Zollinger WD. Serotypes and subtypes of Neisseria meningitidis serogroup B strains associated with meningococcal epitope in the P1.7,16 and P1.1,7 subtype proteins, ${ }^{13,15}$ this indicates that the $\mathrm{P} 1.3$ subtype epitope is present in VR2. Recently, two Norwegian 4:P1.4 patient strains have also been found to carry masked P1.7 epitopes (unpublished results). Studies are in progress to determine if the masked P1.7 epitope found in the strains with other subtypes is caused by a deletion in VR1 similar to that of the $15: P 1.16$ strains.

The demonstration of an inaccessible P1.7 epitope may have consequences for the subtype designation of strains with such epitopes. This implies that strains with masked epitopes will not bind subtype MAbs in routine ELISA and dot-blot typing analyses. We propose to use parentheses to indicate a masked epitope, e.g., P1.(7),16. There are also implications for vaccine development. Antibodies against class 1 proteins seem to be important, as class 1 protein-specific MAbs protected infant rats against bacterial challenge. ${ }^{33}$ Furthermore, sera from vaccinees and patients contained class 1 protein antibodies, ${ }^{34}$ and a correlation was observed between the bactericidal activity of post-vaccination sera and class 1 protein antibody activity. ${ }^{35}$ Thus, it may be of interest to examine whether the P1.7 MAb protects against challenge with strains having a masked P1.7 epitope and also, to determine whether the level of protection afforded by a vaccine with the P1.7,16 subtype protein differs against P1.16 strains with exposed or masked P1.7 epitopes.

We gratefully acknowledge the generous gift of MAbs from Dr F. E. Ashton, Laboratory Centre for Disease Control, Ottawa, Ontario, Canada, and from Dr W. D. Zollinger, Walter Reed Army Institute of Research, Washington D.C., USA. The Norwegian patient strains were collected by Dr E. Holten, Akershus Central Hospital, Nordbyhagen, Norway, and the carrier strains by Drs G. Bjune and J. Eng, National Institute of Public Health, Oslo, Norway. The Chilean strains were a gift from Dr W. D. Zollinger. We thank Ms Karin Bolstad for skilful technical assistance.

disease in Canada 1977-1989. Can J Microbiol 1991; 37 : 613-617.

9. Wedege E, Høiby EA, Rosenquist E, Frøholm LO. Serotyping and subtyping of Neisseria meningitidis isolates by coagglutination, dot-blotting and ELISA. J Med Microbiol 1990; 31: 195-201.

10. McGuinness BT, Clarke IN, Lambden PR et al. Point mutation in meningococcal por $A$ gene associated with increased endemic disease. Lancet 1991; 337: 514-517.

11. Hitchcock PJ. Unified nomenclature for pathogenic Neisseria species. Clin Microbiol Rev 1989; 2 Suppl: S64-S65.

12. Barlow AK, Heckels JE, Clarke IN. The class 1 outer membrane protein of Neisseria meningitidis: gene sequence and structural and immunological similarities to gonococcal porins. Mol Microbiol 1989; 3: 131-139.

13. Maiden MCJ, Suker J, McKenna AJ, Bygraves JA, Feavers IM. Comparison of the class 1 outer membrane proteins of eight serological reference strains of Neisseria meningitidis. Mol Microbiol 1991; 5: 727-736.

14. Tommassen J, Vermeij P, Struyvé M, Benz R, Poolman JT Isolation of Neisseria meningitidis mutants deficient in class 1 (PorA) and class 3 (PorB) outer membrane proteins. Infect Immun 1990; 58: 1355-1359.

15. McGuinness B, Barlow AK, Clarke IN et al. Deduced amino acid sequences of class 1 protein (PorA) from three strains of Neisseria meningitidis. Synthetic peptides define the epitopes responsible for serosubtype specificity. J Exp Med 1990; 171: 1871-1882.

16. van der Ley P, Heckels JE, Virji M, Hoogerhout P, Poolman JT. 
Topology of outer membrane porins in pathogenic Neisseria spp. Infect Immun 1991; 59: 2963-2971.

17. Wedege E, Caugant DA, Froholm LO. Epitopes on the meningococcal class 1 protein. In: Achtman A et al. (eds) Neisseriae 1990. Berlin. Walter de Gruyter and Co. 1991: 153-158.

18. Holten E. Serotypes of Neisseria meningitidis isolated from patients in Norway during the first six months of 1978. $J$ Clin Microbiol 1979; 9: 186-188.

19. Wedege E, Caugant DA, Froholm LO, Zollinger WD. Characterization of serogroup A and B strains of Neisseria meningiridis with serotype 4 and 21 monoclonal antibodies and by multilocus enzyme electrophoresis. J Clin Microbiol 1991: 29: 1486-1492.

20. Abdillahi H, Poolman JT. Whole-cell ELISA for typing Neisseria meningitidis with monoclonal antibodies. FEMS Microhiol Lett 1987: 48: $367-371$

21. Laemmli UK. Cleavage of structural proteins during the assembly of the head of bacteriophage T4. Nature 1970: 227: 680-685.

22. Selander RK. Caugant DA. Ochman H, Musser JM, Gilmour MN. Whittam TS. Methods of multilocus enzyme electrophoresis for bacterial population genetics and systematics. Appl Eniron Microbiol 1986: 51: 873-884.

23. Caugant DA. Bol P. Høiby EA. Zanen HC, Frøholm LO. Clones of serogroup B Neisseria meningitidis causing systemic disease in the Netherlands. 1958-1986. $J$ Infect Dis 1990: 162:867-874

24. Kapperud G. Nesbakken T. Aleksic S. Mollaret HH. Comparison of restriction endonuclease analysis and phenotypic typing methods for differentiation of Yersinia enterocolitica isolates. J Clin Microbiol 1990; 28: 1125-1131.

25. Embley TM. The linear PCR reaction: a simple and robust method for sequencing amplified rRNA genes. Lett Appl Microbiol 1991; 13: 171 174.

26. Mandrell RE, Zollinger WD. Use of a zwitterionic detergent for the restoration of the antibody-binding capacity of electroblotted meningococcal outer membrane proteins. $J$ Immunol Methods 1984; 67: 1-11.

27. Wedege E, Bryn K, Frøholm LO. Restoration of antibody binding to blotted meningococcal outer membrane proteins using various detergents. $J$ Immunol Methods $1988 ; 113$ : $51-59$.

28. Caugant DA, Frøholm LO, Bøvre $\mathrm{K}$ et al. Intercontinental spread of a genetically distinctive complex of clones of Neisseria meningitidis causing epidemic disease. Proc Natl Acad Sci USA 1986; 83: 4927-4931.

29. Klebba PE, Benson SA, Bala S et al. Determinants of OmpF porin antigenicity and structure. $J$ Biol Chem 1990; 265 : $6800-6810$

30. Bentley A, Klebba PE. Effect of lipopolysaccharide structure on reactivity of antiporin monoclonal antibodies with the bacterial cell surface. J Bacteriol 1988; 170: 1063-1068.

31. Pàques M. Teppema JS, Beuvery EC, Abdillahi H, Poolman JT, Verkleij AJ. Accessibility of gonococcal and meningococcal surface antigens: immunogold labeling for quantitative electron microscopy. Infect Immun 1989; 57: 582-589.

32. Caugant DA, Froholm LO, Selander RK, Bøvre K. Sulfonamide resistance in Neisseria meningitidis isolates of clones of the ET-5 complex. APMIS 1989; 97: 425-428.

33. Saukkonen K, Leinonen M, Abdillahi H, Poolman JT. Comparative evaluation of potential components for group B meningococcal vaccine by passive protection in the infant rat and in-vitro bactericidal assay. Vaccine 1989; 7 : 325-328.

34. Mandrell RE, Zollinger WD. Human immune response to meningococcal outer membrane protein epitopes after natural infection or vaccination. Infect Immun 1989; 57: 1590-1598.

35. Wedege E. Frøholm LO. Human antibody response to a group B serotype 2 a meningococcal vaccine determined by immunoblotting. Infect Immun 1986; 51 : 571-578. 